Estudios de la Paz y el Conflicto

Revista Latinoamericana

IUDPAS-UNAH

Volumen 1, Número 1, pp. 116-142

ISSN-e: 2707-8922 / ISSN: 2707-8914

DOI: $10.5377 /$ rlpc.v1i1.9519

Enero-junio 2020

\title{
PAZ Y SEGURIDAD ENGENDRADAS, SUSTENTABLES Y CULTURALMENTE DIVERSAS
}

\author{
PEACE AND SECURITY ENGENDRATED, SUSTAINABLE \\ AND CULTURALLY DIVERSE
}

\author{
Úrsula Oswald Spring \\ Investigadora del CRIM-UNAM \\ uoswald@unam.mx
}

Cómo citar / citation

Oswald Spring, Ú. (2020). "Paz y seguridad engendradas, sustentables y culturalmente diversas", Estudios de la Paz y el Conflicto, Revista Latinoamericana, Volumen 1, Número 1, 116-142. DOI: 10.5377/rlpc.v1i1.9519

\section{Resumen}

El análisis de este artículo relaciona la violencia existente en América Latina con el modelo de desarrollo impuesto, que ha deteriorado el bienestar de las mayorías y su salud humana. El desarrollo de este modelo ha creado inseguridad alimentaria, contaminado aguas prístinas, destruido selvas $\mathrm{y}$ bosques $\mathrm{y}$ ha forzado a millones de personas a abandonar su hogar por las crisis socioeconómicas, la pobreza, la inseguridad pública, el cambio climático y los desastres asociados. Dese una perspectiva de una paz y seguridad engendradas y sustentables el objeto de referencia se puede cambiar del territorio y la soberanía nacional, propia de los conceptos tradicionales político-militares que han resultado en el mundo global en guerras, crisis, miseria y conflictos permanentes. Dese un acercamiento de paz y seguridad engendradas y sustentables, basadas en igualdad y la sustentabilidad, amenazas ya no se causan por otros países y sus armas, sino por el modelo patriarcal dominante que estructuralmente ha desarrollado violencia física, explotación, discriminación y desigualdad. Este texto ofrece un doble objetivo: primero, un marco de análisis sistémico de las condiciones socioambientales y de conflictos emergentes; y segundo, sugiere acciones concretas que promuevan la igualdad, equidad, solidaridad, sustentabilidad ambiental y resolución noviolenta de conflictos dentro de una economía de regalo o economía solidaria en un mundo diverso y sustentable. 


\title{
Palabras clave
}

Paz y seguridad engendrada y sustentable; patriarcado; igualdad; diversidad cultural; sustentabilidad; resolución noviolenta de conflictos; economía de regalo; solidaridad; Antropoceno.

\begin{abstract}
This analysis links the existing violence in Latin America with the imposed development model, which has deteriorated the well-being of the majority of people and their human health. The implementation of this model has contributed to food insecurity, polluted pristine waters, destroyed jungles and forests, and forced millions of people to leave their homes due to socioeconomic crises, poverty, public insecurity, climate change and associated disasters. From an engendered and sustainable peace and security perspective the reference object of territory and national sovereignty may be changed from the traditional political-military conception that often resulted in wars, crises, misery and permanent conflicts. From an engendered and sustainable peace and security approach based on equality and sustainability, threats are no longer caused by other countries and their weapons, but from the dominant patriarchal system that has structurally developed physical violence, exploitation, discrimination and inequality. This text offers both a framework for a systemic analysis of socio-environmental conditions and conflicts; and suggests concrete actions that promote equality, equity, solidarity, environmental sustainability and nonviolent conflict resolution within a gift economy or economy of solidarity in a diverse and sustainable world.
\end{abstract}

\section{Keywords}

Engendered and sustainable peace; patriarchy; equality; cultural diversity; sustainability; nonviolent conflict resolution; gift economy; solidarity; Anthropocene.

\section{INTRODUCCIÓN}

El modelo actual de globalización excluyente y los impactos del cambio climático han puesto la supervivencia de la humanidad y del planeta en duda. La globalización ha acrecentado la desigualdad y mientras que unos 700 millones de personas viven en abundancia, los restantes casi 7 mil millones de personas buscan sobrevivir, a veces en condiciones precarias, insalubres y violentas. El Banco Mundial (BM, 2016) muestra que la riqueza mundial en el planeta ha aumentado durante las pasadas dos décadas, aunque la riqueza per cápita se ha estancado y en la mayoría de los países de América Latina se ha reducido. Esta desigualdad en el ingreso se expresa que en el mismo periodo, la riqueza per cápita fue 52 veces mayor en países desarrollados que en los de ingreso bajo. Asimismo, las mujeres cuentan con menos de $40 \%$ del capital humano mundial por sus salaries más bajos y la no remuneración de sus actividades en el hogar. El mismo BM (2016) estima que lograr mayor igualdad de género aumentará el capital humano global en $18 \%$.

Por otro lado, China, India, Brasil, Venezuela y Argentina redujeron sus niveles de pobreza (BM, 2014) por políticas públicas firmes, aunque en países como España, Grecia, Egipto, entre otros, aumentó la miseria. Durante la Conferencia de Río+20 no se alcanzó ningún acuerdo vinculante entre los gobiernos para conservar al planeta, sólo hubo promesas 
vagas mientras que, simultáneamente, en la VII Conferencia del G-20 ofrecieron US\$ 450 billones al FMI para enfrentar la crisis financiera global, pero no para combatir las amenazas del cambio climático, ni del cambio ambiental global (Brauch et al., 2008). Lo mismo ocurrió en Paris en 2015 y la falta de transparencia en las contribuciones determinadas a nivel nacional (NDC en inglés) puso el aumento de la temperatura global del planeta entre 3 a $4^{\circ} \mathrm{C}$ en 2100, lo que hará invivible gran parte de las tierras en el Sur Global.

A su tiempo, América Latina salió rápido de la crisis global de 2008, gracias a que habían aumentado los precios de las materias primas y la pobreza se pudo reducir en la región, excepto en Honduras y México. Hubo estrategias como el programa "zero fame" en Brasil, que se complementó con ofertas en alimentos básicos, comidas escolares y comedores populares para la población urbana y con el mejoramiento de sueldos, educación, superación del analfabetismo y consolidación de la producción de alimentos que mejoraron el Índice de Desarrollo Humano (IDH). No obstante, fue difícil avanzar significativamente pues los países cuentan con economías frágiles por su alta dependencia de la exportación de materias primas, su débil industrialización y su casi nula innovación. Además, la desigualdad existente ha provocado que la renta nacional se apropiara por una elite en detraimiento de 1@s más necesitad@s. Con la caída de los precios de las materias primas, CEPAL (2019) muestra que los avances se desvanecieron en casi todos los países de América Latina (véase figura 1) con excepción de Bolivia. La pérdida de bienestar y políticas neoliberales en la mayoría de los países han provocado protestas masivas en Chile, Ecuador, Argentina, Colombia y otros, lo que ha obligado a sus gobiernos a retroceder en la agenda de privatización de servicios públicos y de reducción de salarios.

Figura 1: Evolución de la pobreza en América Latina (en millones de personas y \%)

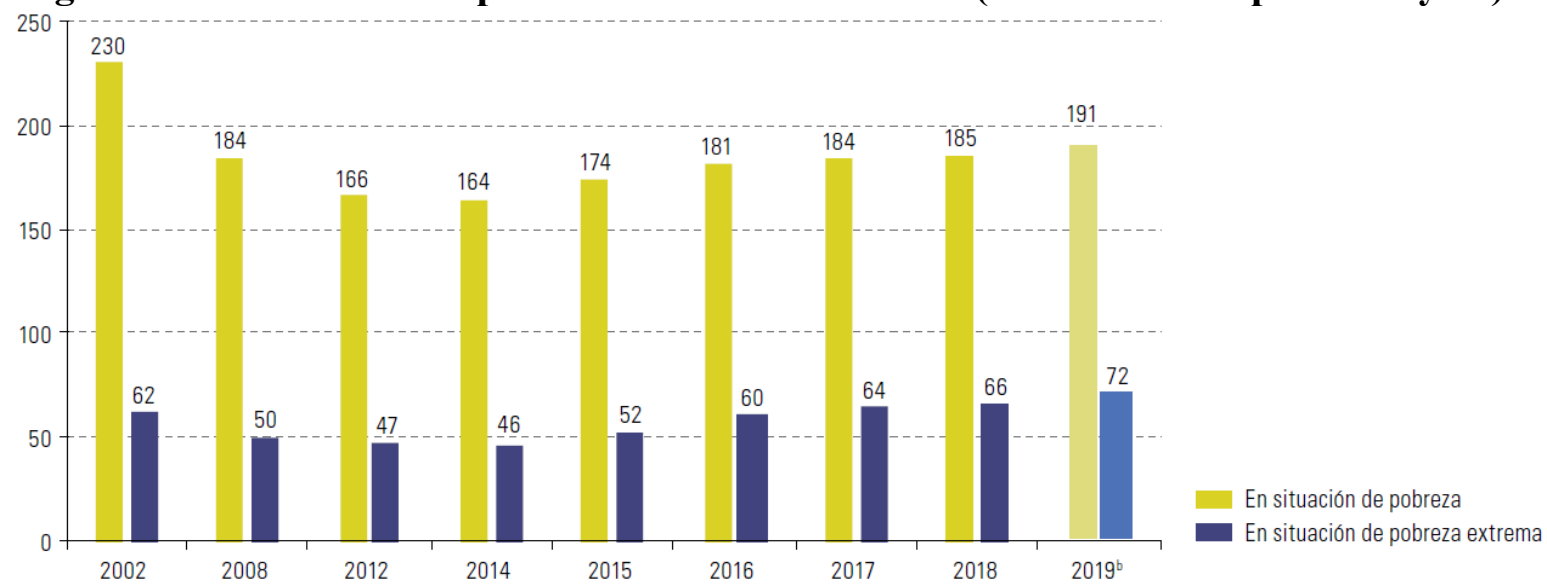




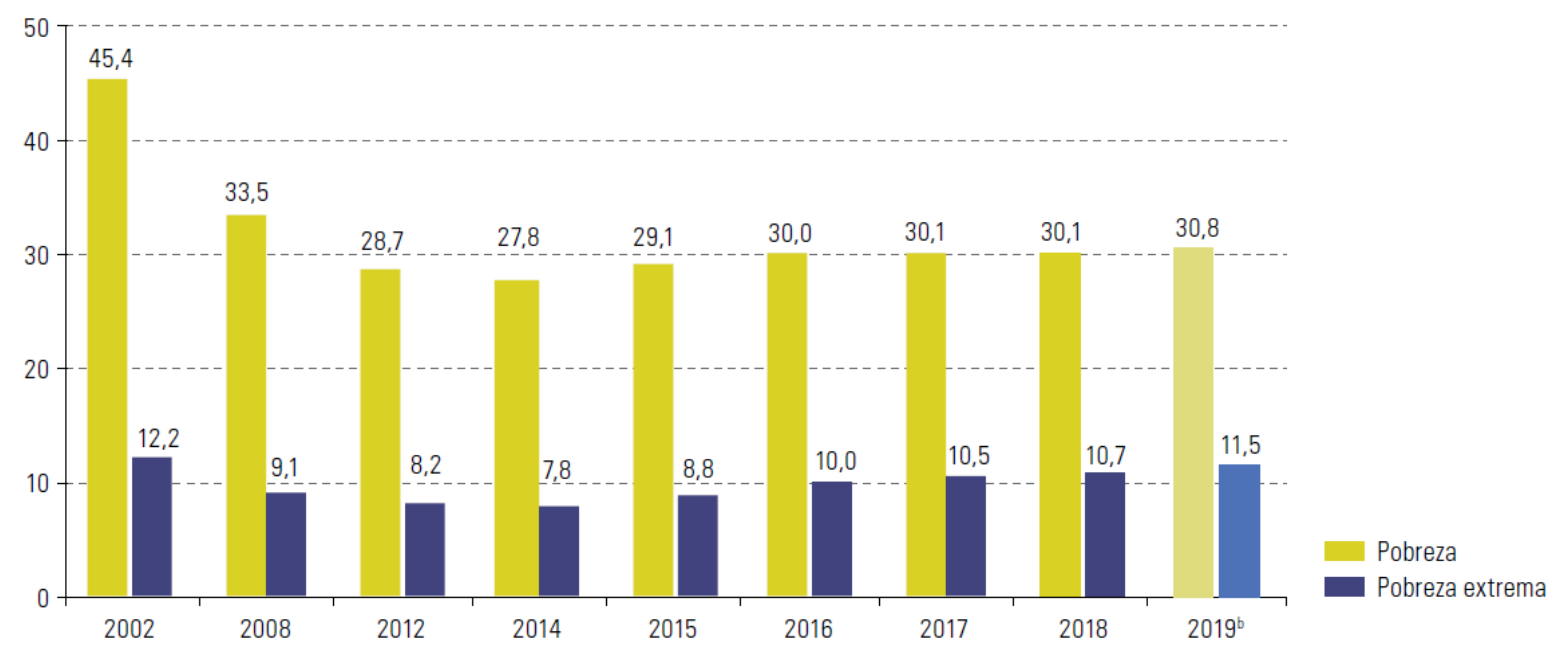

Fuente: CEPAL (2019: 17-18).

En este escenario complejo, el cambio climático es otra amenaza al bienestar y la vida, especialmente de los sectores vulnerables, donde destacan, mujeres, niñ@s, ancian@s y minusválid@s. La alteración de la composición fisicoquímica de la atmósfera por la concentración de gases de efecto invernadero (GEI) ha elevado las temperaturas globales a niveles peligrosos (IPCC, 2018), donde las temperaturas y la acidificación de los océanos nos muestran el rol crucial de los mares para mantener un equilibro frágil en el planeta. No obstante, eventos más extremos y peligrosos ${ }^{1}$ están afectando la vida y el bienestar de la población más vulnerable en el Sur Global, donde la población casi no ha aportado emisiones de los GEI. Aumento en el nivel del mar por desglaciación principalmente en Groenlandia y la Antártida están poniendo en peligro a 300 millones de personas que viven en ciudades costeras, pero la intrusión del mar destruye también agua potable en acuíferos y muchas zonas de alta productividad agrícola por salinización, así como las zonas habitables en islas pequeñas. Vectores (paludismo, dengue, zika, chikungunya) (WHO, 2019), plagas, destrucción de ecosistemas naturales (WWF, 2016), desertificación de suelos (UNCCD, 2019) y aumento en el nivel del mar en pequeñas islas son procesos que retroalimentan negativamente el frágil balance ecosistémico y obligan a crecientes grupos de población a abandonar su modo de vida tradicional y emigrar dentro o fuera del país.

Las tierras fértiles están expuestas a presiones productivas por la agroindustria y por personas que buscan un espacio de vida, donde el aumento de la población y el consumismo con la generación de crecientes montos de basura cada vez más tóxica producen conflictos que se agudizan por la política de extractivismo de grandes empresas transnacionales (Arach, 2018). La interacción entre procesos antrópicos y naturales por el cambio climático aumentan además la incertidumbre, donde Centroamérica y México están altamente expuestos por dos océanos en calentamiento (IPCC, 2019).

Ante este panorama complejo e incierto, el presente artículo analiza estrategias alternativas de gestión de paz y seguridad en un entorno contradictorio y poco alentador en América Latina. Parte de la ampliación y profundización de la seguridad (Oswald y Brauch, 2009) y propone analizar los orígenes de la violencia, de la globalización desigual y de la

\footnotetext{
${ }^{1}$ En 2019 el ciclón tropical Idai ha causado inundaciones devastadoras y pérdidas trágicas de vidas en Mozambique, Zimbabue y Malawi, además de destruir la seguridad alimentaria, las viviendas y el bienestar ante la falta de adaptación y resiliencia de esta población extremadamente pobre.
}

Estudios de la Paz y el Conflicto, Revista Latinoamericana, IUDPAS-UNAH, Volumen X, Número X, enero-junio 2020, pp. 116-142. DOI: 10.5377/rlpc.v1i1.9519 
destrucción del entorno natural, cuyos orígenes se encuentran en el modelo del patriarcado explotador. Después de una pregunta de investigación, el artículo analiza conceptualmente al patriarcado y su incidencia en el modelo capitalista y neoliberal, así como la destrucción del entorno natural y el cambio climático, el surgimiento de una nueva era de la Tierra: el Antropoceno y explora alternativas emergentes de la economía de regalo o solidaria, vivir bien y culturas de paz y seguridad (López, 2004). Conceptualiza las vulnerabilidades socioambientales y los riesgos que se han tornado impredecibles, inesperados, caóticos y no lineares (Beck, 1999). Por primera vez en la historia, la humanidad en su conjunto, pero especialmente la elite transnacional, se conviertan en amenaza a nuestra propia supervivencia, debido al modelo de consumismo que han desarrollado y emitido los GEI. En esta coyuntura el entendimiento tradicional de la seguridad militar, donde el objeto de referencia es la soberanía nacional y la defensa del territorio, pierde centralidad, ya que los seres humanos somos nuestros propios victimarios, pero a la vez somos las víctimas de nuestro modelo de vida insustentable. Ante esta nueva visión de seguridad, se propone una transición hacia la sustentabilidad, que inicia en nichos locales, permea los regímenes políticos y propone transformar la arena global con ajustes en las agendas, actores, actividades y arenas locales y a la vez globales.

\section{MÉTODOLOGÍA}

\section{Pregunta de investigación}

¿Cómo impidió el patriarcado que la humanidad en el siglo XXI pudiera aprovechar sus conocimientos científicos y tecnológicos para vivir en armonía, paz, seguridad y cooperación con los demás dentro de un manejo sustentable de los recursos naturales y con especial cuidado del aire, agua, biota y los suelos?, ¿cómo pudiera una paz y seguridad engendrada y sustentable ofrecer alternativas ante el deterioro severo de la sociedad y el entorno natural?

\section{Objetivos}

Este artículo busca entender por qué el modelo de desarrollo dominante ha deteriorado la salud humana, creado inseguridad alimentaria, contaminado aguas prístinas, destruido selvas y bosques y ha forzado a grupos sociales crecientes a abandonar su hogar por el deterioro socioambiental, el cambio climático y los desastres asociados. El objetivo del presente artículo es superar los conceptos tradicionales de paz y seguridad basadas en lo políticomilitar, que no incluyen los factores estructurales generadores de violencia y destrucción. Al contrario, paz engendrada y sustentable propone análisis y acciones que promuevan la igualdad, equidad, solidaridad y resolución noviolenta de conflictos dentro de una economía de regalo o solidaria.

\section{Conceptos utilizados}

\section{A) Patriarcado}

Esclavitud, feudalismo, racismo y capitalismo, se desarrollaron a partir del sistema patriarcal. El patriarcado emergió a partir de las ciudades-dioses y se consolidó, independientemente, en diferentes partes del mundo (Babilonia, Egipto, China, India y Mesoamérica), cuando se 
logró una acumulación primitiva y excedentes agrícolas, gracias al riego, arado y otros avances tecnológicos en la agricultura. Poco a poco se crearon bases religioso-económicas y políticas hegemónicas, donde se consolidaron los mecanismos de explotación de la mano de obra (esclavitud, trabajadores). Una de sus características fue sustituir el poder de las diosas de fertilidad, hacer invisible el trabajo de las mujeres en el hogar y devaluar el trabajo doméstico y de cuidado. Se perfeccionó e ideológicamente se generalizó al presentarse como única alternativa moderna ${ }^{2}$ para la evolución del mundo. Por ello, la discriminación de género impide ética y socialmente la solidaridad y sustentabilidad, además de que la seguridad de género muestra que la diferenciación sexual no implica orden jerárquico alguno, ningún privilegio y ninguna ventaja. Por el contrario, es socialmente construida y mantiene sistemas consolidados de poder y privilegios con roles y recompensas específicos asignados a hombre y a mujeres. Con el tiempo, los mecanismos de explotación en manos de la élite masculina cambiaron, pero seguía el sistema de dominación y violencia patriarcal. Éste justificó al esclavismo, feudalismo, colonialismo, mercantilismo, capitalismo, domestificación (housewifization de Mies 1986) y neoliberalismo. Actualmente, en el trasfondo del modelo de civilización continúa el patriarcado: autoritario, violento, destructor, excluyente, explotador y discriminador de otros seres humanos, en especial de las mujeres, pero también de los vulnerables y especialmente de la naturaleza.

El Código de Hammurabi (1725 a de C.) es el primer documento escrito en piedra, donde se establecieron roles según el sexo y donde se consolida la discriminación de las mujeres. A partir de esta fecha, se obligaba a las jóvenes de buena familia a conservar su virginidad antes de casarse y so pena de muerte se prohibía a la esposa a tener relaciones extramatrimoniales para garantizar la descendencia de un solo hombre. Ello significaba que las mujeres y niñas estaban obligadas a quedarse encerradas dentro de las casas y podían salir sólo en compañía de algún hombre de la familia, práctica que se repite todavía hoy en muchos países. En la cultura griega también se cambió paulatinamente el matriarcado local hacia un patriarcado local, cuando un semi-dios Zeus se convirtió en el dios todo poderoso sobre la tierra y el cielo, gracias al control tecnológico del relámpago y trueno. Estos cambios promovieron una sumisión mayor de la mujer al despojarla de sus bienes materiales y de la posibilidad de participar en actividades políticas. A partir de la cultura romana se introdujo la herencia del primogénito en línea patrilineal y las religiones monoteístas (cristianismo, judaísmo, islam) consolidaron ideológicamente el rol del varón en semejanza al dios padre todopoderoso, lo que eliminó a las diosas de fertilidad y confinó a la mujer al interior del hogar y al trabajo no remunerado.

Ante este sistema complejo y socio-ideológicamente arraigado, se presentan ahora crisis ambientales descomunales y de civilización, que amenazan la supervivencia de la humanidad misma. Ello hace necesario entender el origen del sistema destructor, deconstruirlo y revertir estas bases profundamente arraigadas. Los cambios paradigmáticos como patrón del avance de la ciencia se presentan sólo vía alguna revolución paradigmática, resultado de succesivas transiciones (Kuhn, 1962). En el caso de la doble crisis -la socioambiental- los enfoques de

\footnotetext{
${ }^{2}$ Margareth Thatcher opinó que ante el neoliberalismo no había alternativa (TINA: there are no alternatives de Maria Mies, 1986); no obstante, las ecofeministas hablábamos de muchas alternativas (TAMA: there are many alternatives). Francis Fukuyama (1992) reforzó políticamente este proceso patriarcal, cuando escribió el fin de la historia al desintegrarse la Unión Soviética en 1989. Entonces para la superpotencia restante, los Estados Unidos, sólo quedó el sistema capitalista en manos de ETN norteamericanos que dominarán al mundo con sus intereses.

Estudios de la Paz y el Conflicto, Revista Latinoamericana, IUDPAS-UNAH, Volumen X, Número X, enero-junio 2020, pp. 116-142. DOI: $10.5377 /$ rlpc.v1i1.9519
} 
una paz y seguridad engendradas tienen el potencial de una transformación radical gracias a su enfoque sistémico holístico que apunta hacia alternativas radicalmente distintas.

Corinne Kumar (2003) infiere que el mundo actual requiere de los universalismos nuevos que reconocen lo universal (valga la redundancia) en los idiomas específicos de las civilizaciones... Universalismos que respetan la pluralidad de las diferentes sociedades, de su filosofía, ideología, tradiciones y culturas; uno que se finca en lo particular, en lo vernáculo pero que encuentra una resonancia en las diferentes civilizaciones y origina nuevas cosmologías.

\section{B) Ampliar y profundizar la paz y la seguridad}

Seguridad es el concepto complementario a la paz. Este se reservó para los estudiosos occidentales durante la guerra fría, mientras que la Unión Soviética centró sus estudios en el término paz. Esa disyuntiva conceptual tuvo repercusiones geopolíticas. La seguridad quedó limitada a una visión militar y política para justificar las guerras representativas en Indochina, Medio Oriente, África y el apoyo a los regímenes militares en América Latina. La amenaza del comunismo había justificado golpes militares, represiones, genocidios y guerras secretas (Laos). Gracias a la industria bélica y sus avances tecnológicos, Estados Unidos se había consolidado como superpotencia y las ETN como el modelo económico único del capitalismo neoliberal. El objeto de referencia se relaciona sólo con el Estado-nación; los valores en riesgo son la soberanía, el territorio y el uso legítimo de la fuerza, y las amenazas provienen de otros Estados, subgrupos (guerrillas), inmigrantes, culturas y religiones ajenas, o sea, hay escasamente una visión incipiente de paz y seguridad negativa. Esta visión limitada de seguridad militar-política ha prevalecido en el análisis científico hasta el fin de la guerra fría.

Al finalizar la guerra fría, el pakistaní Mabhub ul Haq introdujo un concepto profundizado de seguridad humana (PNUD, 1994), que inicia en el ser humano, la familia, la comunidad, el país, la región hasta llegar a lo global, cuyo objeto de referencia se centra en las personas. Los riesgos se vinculan a la supervivencia humana y a las amenazas que provienen del propio Estado (autoritario y represor que comete crímenes de Estado y genocidios), otras naciones, guerrillas, terrorismo y crimen organizado, pero sobre todo, del sistema neoliberal de globalización que ha generado miles de millones de pobres, hambrientos y migrantes.

Esa profundización de seguridad desde el individuo, la familia, la comunidad, el país, la región y hasta el mundo, desató una discusión científica y política. En esta discusión se precisó la conceptualización (Brauch, 2005) de la seguridad humana en cinco pilares: ausencia de miedo; ausencia de necesidades, ausencia de desastre; vivir en un Estado de derecho y vivir en un mundo con diversidad sociocultural. Oswald (2009) introdujo el concepto de seguridad de género que al igual que la seguridad humana se consideran profundizadas al abarcar desde la persona hasta el mundo global.

La Escuela de Copenhague (Buzan y Wæver, 1998) conceptualizó al fin de la guerra fría la ampliación de la seguridad militar-política al incluir la seguridad económica, la ambiental y la social como amenazas nuevas a la seguridad global. En la seguridad ambiental, el objeto de referencia se orientó hacia los ecosistemas naturales, urbanos y rurales; el valor en riesgo es la sustentabilidad y las amenazas son los propios seres humanos con su consumismo y el uso intensivo de hidrocarburos fósiles. Por primera vez, los seres humanos son tanto la amenaza como las víctimas del cambio ambiental global por ese comportamiento irracional (Brauch, et al., 2008).

En la seguridad social o societal, el objeto de referencia se relaciona con las naciones, grupos sociales y los vulnerables. Los valores en riesgo son la igualdad y la identidad nacional, donde las amenazas se vinculan con inmigrantes, culturas ajenas,

Estudios de la Paz y el Conflicto, Revista Latinoamericana, IUDPAS-UNAH, Volumen 1, Número 1, enero-junio 2020, pp. 116-142. DOI: 10.5377/rlpc.v1i1.9519 
fundamentalismos y la falta de tolerancia. La seguridad económica tiene como objeto de referencia el sistema económico y financiero global. Los valores bajo riesgo son la desigualdad, la pobreza y el desempleo, mientras que las fuentes de amenaza se ubican en las crisis económicas, el sistema especulativo, las bolsas de valores, las élites financieras, los paraísos fiscales y la concentración de la riqueza. Los tres tipos de seguridad ampliada: la económica, la ambiental y la societal están amenazadas por las crisis económicas, sociales y ambientales globales.

Finalmente, desde la década de 1960, se ha sectorizado la seguridad al introducir la FAO la seguridad alimentaria, la IEA (2014), la seguridad energética, la Declaración Ministerial del Foro Mundial del Agua 2000, la seguridad hídrica. Oswald (2011) exploró la seguridad de salud más allá de la visión oficial relacionado con guerras biológico-químicas, y durante las dos décadas pasadas, emergieron otras seguridades como la urbana, la rural, la de tránsito entre otras.

Aunque dichas seguridades sectoriales abarcan recursos y procesos vitales de la humanidad y sus procesos productivos, los gobiernos siempre han revisado celosamente estas conceptualizaciones y han impuesto generalmente un sesgo militar-policial a dichas seguridades sectoriales (la seguridad hídrica o alimentario es un asunto de seguridad nacional y no del bienestar de las poblaciones). Por ello, se habla de la guerra energética (Segunda Guerra Mundial), la del agua, la de alimentos, la de salud (bioterrorismo), entre otras.

\section{C) Seguridad y paz engendradas y sustentables}

Queda entonces la pregunta: ¿por qué razón no hemos sido capaces de resolver los conflictos de manera pacífica, cuando tenemos el conocimiento científico y las evidencias históricas que sólo mediante una negociación noviolenta se pueden lograr periodos de paz duraderos? Betty Reardon (2014), estableció el vínculo lógico, estructural y original entre paz, seguridad y violencia y mostró la relación intrínseca entre patriarcado, cultura de guerra, autoritarismo, discriminación y violencia, donde el espacio simbólico público y económico (res pública) se asignó predominantemente al hombre (homo sapiens), mientras que se relegó a las mujeres a la esfera del hogar como homo domesticus (Lagarde, 1990).

El ecofeminismo, introducido por François d'Eaubonne (1974: 10), llamó "la atención por el potencial de las mujeres para iniciar una revolución ecológica" y mostró la interconexión íntima entre los sistemas humanos jerárquicos y la dominación y explotación injustificada de los seres humanos y la naturaleza. Las ecofeministas deconstruyeron el modelo dominante del liberalismo occidental y afirmaron que la reconstrucción tenía que superar el modelo capitalista global, basado en relaciones patriarcales de violencia contra las mujeres, los vulnerables y contra la naturaleza. Surgió entonces el término de paz y seguridad engendradas que representa un paradigma sin violencia, control y destrucción. A partir de la deconstrucción del origen y el proceso de consolidación del patriarcado, así como la estructura de poder inherente dentro de la cual el patriarcado se ha desarrollado y consolidado, se arraigó el capitalismo, la revolución industrial, la urbanización, el neoliberalismo, la globalización y el cambio ambiental global y el cambio climático. Aunque Bennett (2006: 54) argumenta que "el patriarcado puede estar en todas partes, pero no es igual en todas partes, y por lo tanto el patriarcado, en toda su inmensa variedad, es algo que tenemos que entender, analizar y explicar". No obstante, es precisamente esta variedad y la diversidad que ha permitido la evolución del mundo actual androgénico, donde se han superado los diferentes contextos culturales, pero donde el patriarcado ha sido capaz de ejercer mediante mecanismos diversos de control, opresión y explotación de la naturaleza y

Estudios de la Paz y el Conflicto, Revista Latinoamericana, IUDPAS-UNAH, Volumen X, Número X, enero-junio 2020, pp. 116-142. DOI: 10.5377/rlpc.v1i1.9519 
de los seres humanos, el dominio global, el cambio de la historia geográfica del planeta hacia el Antropoceno y el cambio ambiental global.

A partir del concepto de seguridad de género, cuyo objeto de referencia son mujeres, niñ@s, ancian@s, desemplead@s, minusválid@s y tod@s aquell@s que no cuentan con el mismo acceso al poder en relación con el objeto de referencia, se desarrolló la seguridad de género. Los valores en riesgo son las relaciones sociales de género, la igualdad, la equidad y la identidad. Las amenazas provienen del sistema patriarcal, donde élites financieras, gobiernos autoritarios, instituciones discriminatorias e iglesias jerárquicas ejercen su poder mediante mecanismos de control económico, político, religioso e ideológico. No obstante, esta seguridad penetró también en la intimidad del hogar, donde se ejerce la violencia y el control sobre la esposa y 1@s niñ@s y donde los feminicidios son la expresión más dramática de este ejercicio patriarcal violento. Esta seguridad de género, al igual que la humana, tiene niveles profundos desde el individuo y el hogar hasta la globalización excluyente y abarca a las creencias e iglesias andróginas. La cultura patriarcal de poder y violencia es la raíz de la violencia social y ecológica. Corrompió la comunión original entre hombres y mujeres y ahora destroza la armonía entre la humanidad y su hábitat.

\section{D) Antropoceno}

El modelo patriarcal de explotación de la naturaleza dejó huellas profundas durante los últimos 8,000 a partir de la revolución agrícola, pero se agravó con la revolución industrial a partir de 1750 y se agudizó durante los últimos 60 años por el uso masivo de hidrocarburos fósiles. Estos procesos acumulativos llevaron a Crutzen (2002) a hablar de un cambio en la historia de la tierra del Holoceno hacia una época llamado Antropoceno, donde los humanos y sus actividades de extractiviismo, destrucción de selvas y explotación de recursos naturales han cambiado la dinámica integral del sistema tierra.

Este proceso violento de destrucción se opone al concepto ahimsa de los Jaina en la India, vinculado a la paz y seguridad sustentables, donde se controlan los impulsos ancestrales de destrucción mediante la noviolencia activa, el cuidado del entorno natural y la convivencia humana armoniosa con la naturaleza. En Europa, la filosofía de Schumacher (1999) promovió lo pequeño que es bello, algo totalmente opuesto al modelo dominante de la expansión de las empresas transnacionales (ETN) y Czempiel (1986) propuso una estrategia de paz basada en la paz positiva. San Francisco promovió entre sus creyentes un consumismo austero, donde dijo que él "necesitaba poco y lo poco lo necesitaba poco", o sea una filosofía que respeta al entorno natural e impide la acumulación en manos de unos pocos.

Entre1@s investigadores de seguridad y paz, se reflexionó acerca de la biología evolucionaria, donde encontraron que sin el cuidado del ambiente y la negociación pacífica en el acceso de los bienes naturales, no habrá nunca una paz verdadera si no se alcance un hexágono civilizatorio (Senghaas, 1997). Asimismo, la historia de las confrontaciones bélicas en el mundo siempre estaban y siguen estando relacionadas a los recursos naturales, sea territorios, mares, islas, recursos estratégicos (petróleo, gas) y básicos (alimentos, agua).

Al contrario, el capitalismo y sobretodo el neoliberalismo han dejado una huella ecológica gigantesca que equivalía en 2014 a 1.5 de nuestro planeta (WWF, 2016), a pesar de que disponemos de una sola Tierra y no hay otro planeta al alcance todavía que cuente con las mismas condiciones favorables para la vida humana y natural. En el pasado lejano, los registros fósiles mostraron que por cada mil mamíferos, se extinguió uno sólo. La tasa actual de extinción es mil veces mayor que durante la fase anterior, y se estima que el futuro pudiera ser aún diez veces más destructivo que el presente (MA, 2005). Durante las últimos seis

Estudios de la Paz y el Conflicto, Revista Latinoamericana, IUDPAS-UNAH, Volumen 1, Número 1, enero-junio 2020, pp. 116-142. DOI: 10.5377/rlpc.v1i1.9519 
décadas de la historia del Antropoceno, dominado por empresas transnacionales y un consumismo descontrolado de mil millones de personas $(\mathrm{mm})$ acomodadas, hay $6.5 \mathrm{~mm}$ de habitantes que viven en pobreza y con precariedad. Además, nueve millones de $\mathrm{km}^{2}$ de suelo (un área aproximadamente del tamaño de China) fueron moderadamente degradados y tres millones de $\mathrm{km}^{2}$ fueron severamente destruidos, de modo que habían perdido su función biológica original y su fertilidad natural. Sabemos que la salud del suelo es una condición fundamental para los organismos $(\mathrm{FAO}, 2010)$ vivos, pero sobre todo para la producción de alimentos. No obstante, IPCC (2019) en colaboración con FAO descubrió que las mujeres producen $62 \%$ de los alimentos en sólo $2 \%$ de las tierras agrícolas, mientras que los otros $98 \%$ de superficies están destinados a biocombustibles, alimentos balanceados y cultivos comerciales e industriales.

A su tiempo, la plataforma de Siberia Oriental del Ártico tiene un gran balance de hidratos de metano en el fondo marino (entre 50 y 500 Gt de carbono en comparación con los 550 Gt emitido de GEI desde la revolución industrial). El metano, que es un GEI mucho más potente que el $\mathrm{CO}_{2}$, permanece por periodos más cortos en la atmósfera, pero la desglaciación del permafrost pudiera destruir el equilibrio precario existente en la composición fisicoquímica del aire. Algo similar ocurre con el océano que asimila la mayoría de los GEI, pero que tiene acumulado a $2000 \mathrm{~m}$ de profundidad $10^{22}$ joules de energía, que pudiera revertirse, si se alcanzaría la saturación. El riesgo radica en cambios bruscos del clima, que pudieran cruzar los umbrales naturales y provocar puntos de ruptura irreversibles. Datos paleo-climáticos muestran otros calentamientos globales rápidos de $5-6^{\circ} \mathrm{C}$ en pocas décadas, lo que provocó importantes aumentos en el nivel del mar. El surgimiento de fenómenos abruptos en el sistema Tierra relacionado con la liberación abrupta de metano, pudiera generar el colapso del Amazonas o de la Corriente del Golfo, la desglaciación de los polos, un aumento de varios metros en el nivel del mar y la desertificación de las tierras secas en el planeta.

Ante estas amenazas hoy día provocado por la producción y el consumo antrópico, se pone además en riesgo la paz sustentable del planeta, pero se está también afectando mucho más a los países pobres del Sur Global, quienes han contribuido sólo marginalmente a las emisiones de los GEI. Con el fin de retroceder en los peligros potenciales, conservar los recursos naturales necesarios como agua, aire y alimentos sanos, es necesario incluir la reflexión ambiental en el entendimiento de la paz y seguridad. Por ello, la paz y seguridad engendradas y sustentables promueven el diálogo interdisciplinario e intercultural, donde el islam, confucionismo, taoísmo y budismo han integrado la negociación de la paz desde hace miles de años y donde occidente tendrá que aprender de estas culturas milenarias para reducir los peligros y riesgos presentes al conjunto del sistema Tierra.

\section{E) Economía de regalo o solidaria}

La 'economía de regalo', propuesta por Genevieve Vaughan (1997), es una teoría social que constituye un paso hacia la integración de la naturaleza con las actividades humanas. En los servicios ecosistémicos la naturaleza obsequia cotidianamente al entorno y a los humanos diversos bienes y servicios (regula, provee, mitiga y genera servicios culturales). Para comprenderla, Vaughan explica cómo la madre y el padre cuidan a sus hijos, ya que ningún bebé pudiera sobrevivir y convertirse en ser humano sin esta atención. Básicamente, esta teoría busca satisfacer las necesidades de los otros. Insiste que si todos los seres humanos vivieran con decoro, no se necesitaría un mercado que regule y un comercio que gane en esta transacción. En un mundo de suficiencia, se lograría satisfacer todas las necesidades mediante regalos mutuos, similares a los servicios ecosistémicos que la naturaleza nos brinda. 
Por lo mismo, la economía de regalo cuida a uno mismo, a los demás y a la naturaleza. Representa un paradigma alternativo.

Por el contrario, la economía capitalista busca generar ganancias a costa del otro mediante la competencia, la exclusión y la violencia, tres acciones que deterioran las relaciones interpersonales y limitan la paz y seguridad. Sus bases patriarcales la dirigen hacia el ego, el cálculo de cuánto recibo por algo dado y cuánto más puedo ganar a costa de otr@s. Esta economía capitalista-neoliberal produce escasez artificial, lo que permite que sólo unos pocos acumulen mucho, mientras que la mayoría vive en pobreza y miseria.

En ese sistema de acumulación a cualquier costo, ya no se respeta ni a la naturaleza, ni a la especie humana. Los de abajo son estipulado como caóticos, malévolos e incapaces, lo que justifica su subyugación y transformación para servir al proyecto político, socioeconómico, religioso y tecnológico del capitalismo tardío. Tanto a mujeres como a la naturaleza se tienen que oprimir, explotar, expropiar sus recursos socioambientales y transformar el mecanismo de modo tal que se acepte como objeto de referencia la superioridad, la creatividad y la fuerza del sistema dominante neoliberal.

Gracias a esta superioridad, el capitalismo ha aprovechado la economía de regalo mediante mecanismos de explotación, extracción del plustrabajo, remesas y usura en el sistema financiero. Depende, por lo tanto, también de los regalos para mantener su dominio y por ello existe un trabajo doméstico no remunerado en el hogar, básicamente ofrecido por mujeres. No obstante, estos procesos de abuso hace frágil al sistema neoliberal y los llena de contradicciones, por lo que instituciones multilaterales intervienen (FMI, BM, OMC y otras dependencias de la ONU) para proteger este sistema injusto. La crisis actual no es sólo financiera, sino civilizatoria y los extremos por desigualdad, violencia y destrucción ambiental amenazan al sistema mismo. Es precisamente en las crisis y desastres cuando la sociedad exige referencias nuevas y entonces florece la economía de regalo y la libre distribución de bienes y servicios. No es casualidad que se establecen relaciones humanas entre donadores y recibidores, donde no se pregunta por el valor de lo que se obsequia y se recibe, sino se prioriza el intercambio.

Similares condiciones se dan en el cuidado de un bebé, donde el rol de cuidado es básicamente asignado a las mujeres (Serrano, 2010). "Maternar" no es considerada una categoría económica, ya que el sistema no encuentra mecanismos para cosificarlo, aunque los intentos recientes de subrogación de vientres y reproducción asistida van en esa dirección. Una transición sustentable puede encontrarse en la economía de regalo y el maternar a la naturaleza y los seres humanos como vías alternativas para superar las crisis. Como modelo de distribución está presente en todas las sociedades, porque la biología del bebé lo requiere, al ser incapaz de satisfacer sus necesidades propias y de desarrollarse como humano. Estos regalos se han invisibilizado, pero son el origen de las relaciones humanas profundas entre hijos, madres y padres. Esta interrelación entre cuidar, estar para otros y asumirlo como suyo, representa valores profundos y es parte fundamental de lo humano. Abre caminos hacia un mundo diferente, donde se valoran los bienes de subsistencia, los mercados locales, el trueque, la diversidad cultural, el cuidado ambiental y el bienestar social.

Vaughan (1997) insiste que la interacción del regalo es transitivo y crea una relación de inclusión entre el donante y el receptor. Dar regalos implica valorar al otro y a sí mismo. Dar regalos es más cualitativa que cuantitativa y está orientada hacia el otro en lugar de ser egoorientada, por lo que es inclusivo y no exclusivo. De acuerdo con la autora, la economía de regalo se ha generalizado en muchas comunidades en todo el mundo y se practica sin reconocimiento especial. Al promover este paradigma alternativo se inician cambios

Estudios de la Paz y el Conflicto, Revista Latinoamericana, IUDPAS-UNAH, Volumen 1, Número 1, enero-junio 2020, pp. 116-142. DOI: 10.5377/rlpc.v1i1.9519 
conscientes en la sociedad que pueden propagarse y que priorizan al valor de uso sobre el valor de cambio del sistema capitalista.

\section{F) Vivir bien}

La cultura aymara en Bolivia, Perú y parte de Chile lanzó un nuevo reto al consumismo al otorgar en Bolivia los mismos derechos constitucionales a la naturaleza que a los seres humanos. El pensamiento indígena diferente en esta región andino-amazónica aborda la vida desde una postura holística y obliga a repensar el paradigma económico dominante del neoliberalismo, donde sólo el dinero y la acumulación cuentan. El pueblo aymara llamó a la comprensión de la complementariedad sumak qamaña (vivir bien) o del sumak kawsay (buen vivir), desde los tiempos incaicas. Desde un entendimiento plurinacional, estos grupos indígenas han promovido un Estado diverso que puede fortalecer la equidad y aumentar la igualdad entre la sociedad indígena y cuidar a la vez la naturaleza para promover la sustentabilidad.

La constitución moderna de Bolivia (2009) incluye normas indígenas tradicionales para promover los derechos humanos, sociales y naturales, pero sobre todo mayor igualdad a los indígenas y su cultura. La 'Madre tierra' (pachamama) se considera más que una reserva natural en un espacio específico protegido por reglas de conservación especiales (Gasca, 2014), dado que el concepto contiene un componente espiritual. Pachamama incluye la gestión ambiental, social y cultural, donde prevalece la solidaridad y la cooperación en lugar de la competencia y el meollo de esta epistemología nueva integra lo económico de manera holística a la vida cotidiana. "De la reproducción del capital, centro de las teorías del desarrollo y de sus prácticas, se pasa a colocar la reproducción de la vida como el eje de comprensión del proceso de reproducción en su conjunto, y como el criterio organizador de lo económico, que dejaría a la vez de ser considerado una dimensión escindida" (Ceceña 2014: 11). El sumak kawsay o sumak qamaña ponen límites al crecimiento, con lo que estas sociedad indígenas se enfrentan al desarrollo neoliberal único al modificar de raíz la lógica general de la reproducción materialista dominante, por lo que se vinculan conceptualmente a la economía de regalo.

\section{G) Culturas de paz y seguridad}

Con base en la Resolución A/52/13 (ONU, 1998), la UNESCO (2013) promovió un año de cultura de paz que se amplió hacia una década, entendida ésta como el acercamiento integral que previene la violencia y los conflictos bélicos. Representa una alternativa a la cultura de guerra andrógina, con fundamento en la educación para la paz, promoción del desarrollo sustentable, económico y social, respecto a los derechos humanos, igualdad y equidad de género, participación democrática, tolerancia, flujo libre de información y desarme. Consiste en una serie de valores, actitudes y comportamientos que rechazan la violencia y negocian los conflictos, tratando de atacar sus causas para solucionar los problemas mediante el diálogo y la negociación entre las personas, los grupos y las naciones (ONU, 1999).

Con el fin de consolidar la cultura de paz, la ONU declaró "Década de Cultura de Paz" entre 2000 y 2010. Durante ese período, las potencias occidentales y comunistas promocionaban la paz y seguridad, pero sin tomar en cuenta el ambiente pues sus guerras siempre se relacionaron con la apropiación de tierras, agua, petróleo, oro y otros minerales estratégicos. Estos conceptos siguen siendo profundamente autoritarios y no consideraban los seres humanos dentro de su entorno natural. En sociedades asiáticas (los Jaina) e indígenas, la relación fue históricamente más armoniosa entre los humanos y la naturaleza, 
lo que ha permitido el desarrollo de grandes civilizaciones, la consolidación de diversos productos alimentarios y, con ello, una paz y seguridad sustentables.

Cultura de paz incluye un conjunto de valores diversos, tradiciones, comportamientos, actitudes y formas de vida con respeto a la vida en la tierra y para los seres humanos (UNESCO, 2013). Los conflictos entre los seres humanos, las comunidades y los estados deberían ser gestionados a través de la resolución de conflictos, donde las representaciones sociales discriminatorias y la violencia se terminan mediante la negociación que puede llevar a un ganar-ganar en las condiciones para todos los involucrados. En este sentido constructivo, una cultura de paz debería promover la educación y consolidación de la paz con el fin de profundizar el diálogo y aumentar la cooperación entre las razas, sexos y edades.

Incluye el respeto a la vida, el fin de la violencia y la promoción y la práctica de la noviolencia mediante la educación, el diálogo y la cooperación. Reafirma el pleno respeto de los principios de soberanía, integridad territorial e independencia política de los Estados y la no intervención en los asuntos que son esencialmente de la jurisdicción interna de los Estados, de conformidad con la Carta de las Naciones Unidas y el derecho internacional. Reafirma el pleno respeto y promoción de todos los derechos humanos y las libertades fundamentales, el compromiso de la solución pacífica de los conflictos, los esfuerzos de satisfacer las necesidades de desarrollo y ambientales de las generaciones presentes y futuras, el respeto y la promoción del derecho al desarrollo de todos los habitantes en el planeta, incluidos los más vulnerables, la promoción de la igualdad de derechos y de oportunidades entre mujeres y hombres, la promoción del derecho de toda persona a la libertad de expresión, opinión e información, así como la adhesión a los principios de libertad, justicia, democracia, tolerancia, solidaridad, cooperación, pluralismo, diversidad cultural, diálogo y entendimiento a todos los niveles de la sociedad y entre las naciones; animados por un entorno nacional e internacional propicio que sí fomenta la paz.

\section{3. ¿CÓMO SE HA RECONCEPTUALIZADO LA SEGURIDAD?}

\section{Seguritización}

Ole Waever (2008), desarrolló el concepto de 'seguritización' al declarar un evento de tan extrema emergencia que justifique el uso de medidas extraordinarias aceptadas por la audiencia o el pueblo. De acuerdo con este autor, el proceso de seguritización requiere de tres componentes:

1. Un actor que seguritiza, o sea una entidad que promueve el movimiento de seguritización, generalmente un líder nacional o internacional.

2. Un objeto de referencia que está amenazado y cuyos valores tienen que protegerse con medidas extraordinarias, generalmente invasiones, guerras, terrorismo y eventos bélicos.

3. Una audiencia hacia quien se dirige el acto de seguritización y que acepta la amenaza existencial hacia el objeto de referencia, a pesar de sufrir las medidas extraordinarias impuestas.

El movimiento de seguritización es exitoso sólo cuando la audiencia acepta las medidas y restricciones en su vida cotidiana, con el fin de conservar sus valores para mantener sus activos vitales (p.e. la guerra contra el terrorismo de la administración George W. Bush que sigue justificando las invasiones de Irak, Siria y muchas más).

Estudios de la Paz y el Conflicto, Revista Latinoamericana, IUDPAS-UNAH, Volumen 1, Número 1, enero-junio 2020, pp. 116-142. DOI: $10.5377 /$ rlpc.v1i1.9519 


\section{Paz sustentable y seguridad ambiental}

Las emisiones de GEI se producen por la adición de los humanos a los energéticos fósiles que alteran la composición química de la atmósfera. En noviembre 2019, los compromisos incondicionales de los países firmantes de París, llevarán al mundo a un incremento de $3.2^{\circ} \mathrm{C}$, lo que aumentará las sequías en Centroamérica y parte de México, noreste de Brasil, Perú y hará otros países inhabitables y sin posibilidad de producir sus alimentos. Los países del G20 producen $78 \%$ de los GEI y 15 de estas naciones no se han comprometido a una fecha para cero emisiones. Las emisiones de GEI en 2018, incluyendo el cambio de uso de suelo forestal, llegó a un máximo de 55.3 gigatoneladas (Gt). Para limitar el aumento de temperatura arriba de $2^{\circ} \mathrm{C}$ se requiere reducir $15 \mathrm{Gt}$ y para llegar a un incremento de $1.5^{\circ} \mathrm{C}$ se necesitan $32 \mathrm{Gt}$ menos. Si no se reduce anualmente entre 2020 y $20307.6 \%$ de los GEI, el mundo no alcanzará esta meta necesaria para proteger a las pequeñas islas en el Caribe y el Pacífico y todas las ciudades en la costa.

Reforestación masiva y tecnologías de reducir y capturar los GEI existen, pero falta la voluntad política para implementar las políticas públicas y empresariales para alcanzar la meta de mantener el aumento de la temperatura en $1.5^{\circ} \mathrm{C}$. A pesar de que las energías renovables se han cuadruplicado entre 2009 y 2019 con una inversión de 2.6 billones de dólares, todavía falta avanzar más, además de que en los países industrializados sigue predominando el biocombustible que compite con selvas o bosques, tierras y agua. Asia representó $61 \%$ del total de instalaciones nuevas de energía renovable y aumentó la capacidad instalada de energía renovable en un $11.4 \%$ en 2018. África generó $8.4 \%$ de crecimiento y casi dos tercios de toda la generación de energía añadida en 2018 procedían de fuentes renovables, lideradas por economías emergentes y en desarrollo (IRENA, 2019).

Otro tema crucial del cambio climático es la mayor acidificación de los océanos, los que ahora absorben la mayoría del $\mathrm{CO}_{2}$ emitido, lo que pudiera llevar a la tierra hacia puntos posibles de ruptura. Al crecer la temperatura en el mar aumenta el nivel del mar por el deshielo de la Antártida, Groenlandia y glaciares, por lo que especies marinas pierden su hábitat y se alteran las migraciones que requieren de temperaturas más frías. En la parte terrestre, se alteran los ecosistemas y muchas plantas y animales van a desaparecer por las temperaturas más elevadas. El conjunto de estos procesos marinos y terrestres incide en la producción de alimentos humanos y ante sequías extendidas, la población busca sitios más propicios ante un dilema de supervivencia. El resultado son migraciones internas y externas, conflictos y violencia de género, donde los países generadores más importantes de GEI son cada vez menos dispuestos a recibir refugiados ambientales y de violencia.

\section{HUGE: una gran seguridad humana, de género y ambiental}

Al interrelacionar la seguridad ampliada y profundizada, Oswald (2009) desarrolló una seguridad compuesta por seguridad humana, de género y ambiental (HUGE en inglés). Interrelaciona los cinco pilares de la seguridad humana (ausencia de miedo, de necesidades, de desastres, vivir en un Estado de derecho y con diversidad cultural) con el concepto de seguridad de género que incluye a tod@s que no tengan el mismo acceso al poder. Como concepto holístico, esta HUGE seguridad es un concepto analítico y de acción. Incluye la seguridad ambiental, donde un entorno sano, el manejo sustentable de los bienes naturales y las prácticas de remediación, deberían lograr una adaptación capaz para reducir la doble

Estudios de la Paz y el Conflicto, Revista Latinoamericana, IUDPAS-UNAH, Volumen X, Número X, enero-junio 2020, pp. 116-142. DOI: 10.5377/rlpc.v1i1.9519 
vulnerabilidad socioambiental (Oswald, 2013). Centra su objeto de referencia en los humanos y la naturaleza, mediante la gestión de paz, sustentabilidad, equidad de género e igualdad entre todos los seres humanos.

HUGE explora los procesos que pudieron reorientar las acciones de seguridad humana hacia la igualdad, equidad y desarrollo sustentable, donde se mitigan los eventos extremos y se reducen los desastres con medidas preventivas, pero donde se incluye también la sabiduría de los pueblos ancestrales para manejar la sociedad y el entorno natural. Participarían en estos procesos globales organizaciones sociales e inversiones privadas en manos de empresarios éticos para consolidar una gobernanza participativa y el reforzamiento de las leyes y normas, que se convertirán en promotores de políticas de igualdad. Asimismo, HUGE estimula la participación sociopolítica y económica de mujeres y grupos menos favorecidos.

\section{TRANSICIÓN HACIA LA HUGE PAZ Y LA SEGURIDAD ENGENDRADAS Y SUSTENTABLES: UN CAMBIO PARADIGMÁTICO}

Confrontados con riesgos desconocidos, la ciencia y la tecnología han avanzado vertiginosamente en el siglo pasado y presente. Las computadoras quánticas abren potencialidades de superposición (qubits), de interrelaciones (entanglement) entre tiempo y espacio y de amplitudes (amplitudes) que rebasen las probabilidades de la física clásica, pero que implican también potenciales riesgos por errores imprevisibles. A su tiempo, la tecnología militar ha permeado la vida civil (microondas, internet, nanotecnología, genética, inteligencia artificial, clonación). Por ello Ulrich Beck (2011) ha demostrado que nuevos conocimientos en ciencia y tecnología traen consigo amenazas desconocidas, donde los riesgos son cada vez más complejos, impredecibles, no lineares, caóticos y en cascada.

La sociedad tampoco tiene el tiempo para adaptarse a esas complejidades desconocidas, por lo que se requiere de procesos precautorios y acciones preventivas para no caer en riesgos descomunales. Sin embargo, los gobiernos, las empresas y la sociedad privilegian hasta ahora acciones reactivas, que muchas veces llegan demasiado tarde. Por ello hubo desastres en cascada como el terremoto en Fukushima, Japón, seguido por un tsunami que rompió las paredes de protección de la central nuclear, no sólo por lo alto y fuerte de las olas, sino también por la corrupción en el diseño de los muros de protección. La carencia de medidas preventivas adicionales facilitó la destrucción de los sistemas de enfriamiento y se fundieron dos reactores nucleares. Para evitar una fundición de todo el complejo y una catástrofe mayor, se enfriaban los reactores nucleares con agua del mar. El agua contaminada con radioactividad se vertió al Océano Pacífico y llegó hasta el continente americano, o sea se contaminó el mar más grande del planeta. Este desastre en cascada mostró que algunas catástrofes pueden afectar lugares lejanos e incluso, al planeta entero (GEI con calentamiento global).

Las calamidades recuerdan que la vida y el sistema natural están interconectados en todo el planeta y no pueden prevenirse por tecnologías, aunque sean de vanguardia. Beck (1999), insistió que la misma tecnología genera riesgos desconocidos (plantas nucleares, organismos genéticamente modificados, emisiones de GEI, geoingeniería, células madres, inteligencia artificial, computadoras cuánticas, entre otras).

En síntesis, significa que hay que liberarse de la ilusión que la vida y la naturaleza pueden ser sustituidas por procesos artificiales (robótica). Más aún, hasta ahora no hay en el sistema solar algún otro astro con la misma calidad de vida y belleza, lo que implica reconocer que

Estudios de la Paz y el Conflicto, Revista Latinoamericana, IUDPAS-UNAH, Volumen 1, Número 1, enero-junio 2020, pp. 116-142. DOI: 10.5377/rlpc.v1i1.9519 
en el universo conocido sólo existe este único planeta, lleno de existencia y que es urgente tomar medidas para salvarlo y protegerlo ante intereses mezquinos que provocan la destrucción humana y generaron el Antropoceno.

La desigualdad, aún en países industrializados (p.e. Estados Unidos), ha generado efectos negativos al conjunto de la sociedad, produjo violencia, números elevados de personas con depresión, angustia y enfermedades físicas o mentales. La falta de paz integral exige renunciar a la cosmovisión gnóstica metafísica occidental, basada en la filosofía patriarcal del idealismo-materialismo que centra todos sus esfuerzos sólo en el varón. Significa deconstruir las ideologías subyacentes que generan desigualdad; minimizan los impactos por políticas; modelos económicos concentradores de riqueza; tecnologías e instituciones religiosas, políticas y civiles que consolidan el sistema patriarcal. Ello involucra renunciar al egoísmo y a la identidad competitiva y, por el contrario, a promover la igualdad entre grupos sociales, etnias y regiones pero también entre grupos etarios y género.

Ese cambio paradigmático significa erradicar la guerra, la violencia, la concentración de riqueza ${ }^{3}$ y el poder sobre los demás y sobre los procesos naturales. En cambio, abre caminos de aprendizaje que supera "el elitismo teoricista y el basismo practicista, y restablece la unidad o la relación teoría y práctica" (Freire, 1968: 34). Permite aprender de mujeres, indígenas y personas de la tercera edad, que cuentan con amplios conocimientos tradicionales, así como visibilizar el paradigma de la economía de regalo (Vaughan, 1997) y reconocer su importancia en la vida diaria. Aún en Estados Unidos, 38\% de su PIB se crea por trabajo no remunerado, básicamente en manos de mujeres-amas de casa y cuidadoras. Ningún país podría sobrevivir sin estos aportes invisibilizados, pero cruciales en el bienestar y calidad de vida de toda la sociedad.

\section{Cambio paradigmático}

Al preguntar cómo iniciar un cambio paradigmático en la paz y seguridad, existe un potencial en la educación para la paz con cursos prácticos que fortalecen la colaboración entre investigadores y activistas de la paz (Reardon y Snauwaert, 2014). Promueven desde abajo un mayor balance entre géneros, clases, etnias y regiones, al integrar sabidurías ancestrales tradicionales con conocimientos universitarios y resultados de investigación.

En la seguridad ambiental hay que promover alternativas al modelo capitalista de business-as-usual y entender que estas ya están presentes (energía renovable, reciclamiento de desechos sólidos, agricultura orgánica, reúso y reciclamiento de bienes). Solo la opción de descarbonizar y desmaterializar los procesos productivos y el consumo permitirá contener las amenazas del cambio climático. Pero esta economía circular implica esfuerzos coordinados entre sociedad, empresarios y gobiernos. Existen alternativas en forma de energía renovable (solar, eólica, mareomotriz y biomasa de segundo nivel). Estas renovables eliminan las externalidades, son altamente competitivas con el uso de energías fósiles y son económicamente más baratas. No obstante, subsidios e inversiones de largo plazo en energías fósiles y en fracking han impedido una transición rápida hacia las energías renovables.

Los reportes del IPCC (2014) muestran que 97\% de los científicos climáticos opinan que el calentamiento global y el cambio climático ocurrido durante el último siglo, es causado

\footnotetext{
${ }^{3} \mathrm{Al}$ igual que en la economía mundial 85 personas controlan la misma riqueza que 3.5 mil millones de personas (PNUD, 2014), en México 10 billonarios acumulan 132.9 mil millones de USD (Forbes, 2014) y controlan la bolsa de valores.

Estudios de la Paz y el Conflicto, Revista Latinoamericana, IUDPAS-UNAH, Volumen X, Número X, enero-junio 2020, pp. 116-142. DOI: 10.5377/rlpc.v1i1.9519
} 
por actividades humanas y emisiones de GEI. Sólo una transición rápida y radical hacia una descarbonización evitaría que los GEI en la atmósfera cambiarán el clima global del planeta, lo que provocaría sequías catastróficas con límites en el acceso al agua por periodos largos, pero donde también lluvias torrenciales destruyeran directamente la seguridad alimentaria y la biodiversidad.

Otro cambio paradigmático vincula la paz y la seguridad con la producción y el consumo de alimentos. En pleno siglo XXI, todavía mueren 25 mil personas a diario por hambre, principalmente niñ@s, pese a que la producción de arroz, trigo y maíz ha aumentado entre $66 \%$ y $88 \%$ sólo en Latinoamérica y Asia. Paradójicamente, cerca de $40 \%$ de los alimentos producidos se pierde en países industrializados y emergentes (FAO 2014). Los costos directos de los desechos ascienden a un billón de USD/año y si se incluyen los costos indirectos ${ }^{4}$ en bienestar, ambiente, conflictos y salud, el desperdicio de alimentos causa un daño anual de 2.6 billones de USD, equivalente al PIB de Francia. América Latina genera $6 \%$ de las pérdidas mundiales de alimentos y la región pierde por lo menos $15 \%$ de sus alimentos disponibles: $28 \%$ en el consumo, $28 \%$ en la producción, $22 \%$ en el manejo y almacenamiento, $17 \%$ en el mercado y distribución y $6 \%$ durante el procesamiento, lo que permitiría satisfacer las necesidades alimenticias de 30 millones de personas, es decir, 64\% de quienes sufren hambre en la región (FAO, 2014).

El maíz es uno de los alimentos más importantes en el mundo, además de ser el alimento básico de los pueblos indígenas en América Latina. Se utiliza ahora mayormente en la producción de bioetanol, fibra y alimentos balanceados (dextrosa, bebidas alcohólicas, antibióticos, alta fructuosa en forma de jarabe de maíz, glucosa, aceites, almidón, papel, tintes comestibles, pasta de dientes y otros). A su tiempo, IPCC (2019) apoyado por FAO, encontró que las mujeres producen $62 \%$ de los alimentos consumidos en el mundo en sólo $2 \%$ de tierras, sus huertas familiares o pequeñas parcelas, mientras que el resto de la producción alimentaria es comercial e industrial. Al apoyar a las mujeres con créditos y tecnología verde se pudieras regionalmente resolver el problema del hambre, reducir los desechos alimentarios y evitar la desnutrición crónica de niñ@s recien nacid@s con daños cerebrales irreversibles.

Además, la transición hacia una alimentación natural con menos cárnicos representa un camino individual y colectivo hacia una paz engendrada y sustentable. La siguiente figura (Figura 2) muestra dos consumos metabólicos totalmente distintos: una familia campesina en el Altiplano de Perú y una familia de clase media en Alemania. Mientras que la primera vincula la producción con el consumo y el reciclamiento de los desechos que se incorporan como abono en el proceso productivo, la familia alemana consume productos industrializados con desechos industriales, que causan un elevado impacto ambiental.

\footnotetext{
4 FAO (2014) estima las pérdidas directas en alimentos en 1 billón (mil millones de USD); los costos ambientales: $700 \mathrm{MM}$; los sociales: $900 \mathrm{MM}$; 3.5 Gt de $\mathrm{CO}_{2}$ : $394 \mathrm{MM}$; agua: $164 \mathrm{MM}$; erosión del suelo: 35 MM; daños a la biodiversidad por pesticidas: $32 \mathrm{MM}$; conflictos causados por erosión de suelos: 396M; pérdida de bienestar: 333MM; impactos en salud: $153 \mathrm{MM}$ con un total de 2.6 billones de USD.
}

Estudios de la Paz y el Conflicto, Revista Latinoamericana, IUDPAS-UNAH, Volumen 1, Número 1, enero-junio 2020, pp. 116-142. DOI: 10.5377/rlpc.v1i1.9519 
Figura 2: Metabolismo del consumo en Perú y Alemania.
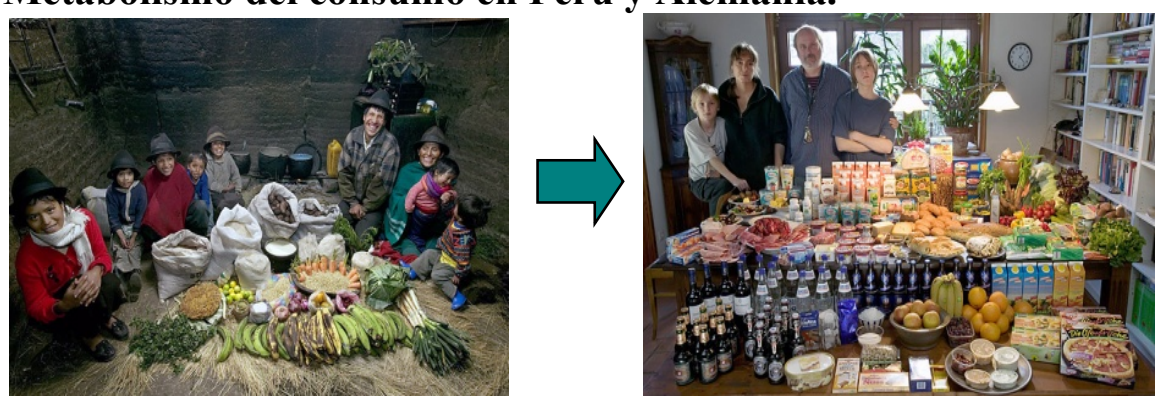

Por lo tanto, una transición en manos de la gente implica un cambio en la dieta de proteínas animales hacia proteínas vegetales. La capacidad de la tierra de soportar el modelo alimentario occidental con consumo de carne diariamente permite abastecer sólo a cinco mil millones de personas, no obstante, ya existen 7.5 miles de millones de ciudadanos en el planeta. Esto significa que el modelo occidental dominante de business-as-usual no puede generalizarse y sólo con una dieta basada en vegetales el planeta pudiera alimentar a 15 mil millones de habitantes.

La tercera transición en manos de gobiernos y ETN se relaciona con la reducción y posterior supresión del gasto militar que asciende a 2.5\% del PIB mundial por año. Este gasto global llegó en 2018 a 1,822 mmd de dólares o un aumento de $2.6 \%$ con respecto al año anterior. Se estima que 249 USD/cápita/año de inversión en el mundo serían suficiente para superar la pobreza de tres mil millones de personas que viven hoy con menos de $2.5 \mathrm{USD} /$ día y permitirá elevar además la calidad de vida de $80 \%$ de la población mundial que vive con menos de 10 USD por día. Al invertir los gastos militares en energía renovable, producción sustentable de alimentos, conservación de agua, recuperación de suelos y ecosistemas dañados, educación y salud para tod@s, la calidad de vida de los habitantes del planeta mejoraría y se podrían preventivamente erradicar epidemias, contaminación y cambio climático.

La cuarta transición hacia una paz engendrada y sustentable, se relaciona con los mecanismos de redistribución de los ingresos y la riqueza en el planeta. Tanto las crisis financieras de 1929 como las del 2008, ocurrieron cuando hubo la más elevada desigualdad en el ingreso entre $1 \%$ de los hogares más pobres y los más ricos, lo que ha aumentado además las deudas domésticas de los que menos tienen. Para reducir esta desigualdad es necesario actuar en la arena política y promover mecanismos fiscales que permitan aumentar progresivamente los impuestos sobre ganancias y redistribuir estos recursos de manera transparente en calidad de educación, bienestar y salud pública entre los sectores desprovistos.

Los países en América Latina no sólo son de los más desiguales, sino que también tienen un índice elevado de corrupción, ineficiencia y bajo nivel de servicios públicos, además de presentar los más altos índices de violencia. El continente americano aporta anualmente 400 billones de USD como resultado de actividades ilegales (tráfico de drogas, humanos, órganos, arqueología, arte, pornografía, extorsión, secuestro, órganos, cobro de piso y corrupción), que se blanquean en el sistema financiero mundial, básicamente norteamericano. Esto ocurre porque hay gobiernos permisivos y corruptos, además de sistemas financieros poco transparentes y paraísos fiscales que blanquean estos dineros sucios. Esta transición obligaría a Estados industrializados promover cambios en el sistema financiero internacional, donde p.e. el impuesto Tobin o ITF (Impuesto sobre las Transacciones Financieras) pudiera

Estudios de la Paz y el Conflicto, Revista Latinoamericana, IUDPAS-UNAH, Volumen X, Número X, enero-junio 2020, pp. 116-142. DOI: 10.5377/rlpc.v1i1.9519 
estabilizar los flujos especulativos, transparentar el flujo ilegal e impedir las reiterativas crisis financieras del siglo pasado y presente.

Una quinta transición se relaciona con el tema de equidad de género. Más de cinco mil años de relaciones patriarcales han consolidado roles diferenciales según el sexo masculino y femenino, lo que ha consolidado socio-culturalmente representaciones sociales y actividades que han impulsado a las mujeres a auto-asignarse roles en el hogar y el cuidado. El conjunto de la sociedad andrógina en diferentes partes del mundo ha naturalizado estas diferencias como innatas, a pesar de que son socialmente construidas y pueden cambiarse. Iglesias, elites financieras masculinas y gobiernos autoritarios en todo el mundo han reforzado ideológicamente este modelo de discriminación de género, al relegar a las mujeres al interior del hogar, donde se ha invisibilizado su trabajo sin pago (Lagarde, 1990).

Las mujeres, al igual que otros bienes, son aún consideradas botín de guerra y su violación es promovida por mandos militares. Durante conflictos armados, los cuerpos de las mujeres se convierten en campos de batalla y, en diferentes partes del mundo, la violencia sexual contra una mujer o un grupo tuvo como meta humillar y desmoralizar al enemigo. Esta violencia de guerra representa también un ataque y denigración al varón: mediante el abuso del cuerpo de su mujer se viola su honor y su derecho exclusivo de posesión sexual, una visión típica del sistema patriarcal dominante. Además, esta violencia sexual tiene como fin dejar marcas genéticas de victoria en la descendencia de las mujeres que han sufrido la violencia sexual durante la guerra.

No obstante, la violencia contra las mujeres se presenta también durante los llamados periodos de paz. En Guatemala por ejemplo, la violencia de género continúa de tal manera aún después de la firma de los Acuerdos de Paz Firme y Duradera en 1996, y las violaciones y sobre todo, las tasas de feminicidios actuales son similares a las identificadas durante la década de 1980 en plena guerra civil. Se estima que cada tercera mujer en el mundo es golpeada y cada quinta es violada, muchas veces, de forma tumultuarias. Se estima que 70\% de las mujeres sufren violencia física o sexual y más de la mitad de los feminicidios en el mundo es perpetrada por parte de sus parejas íntimas. Los feminicidios son totalmente distintos a los asesinatos de varones. A las mujeres se les considera como objeto de desprecio, lo que justifica una brutalidad excepcional que incluye violación con dolor, mutilaciones y torturas antes de su asesinato.

En situaciones militarizadas (Argentina, Guatemala, Chile), o de terror de Estado y guerra contra el narcotráfico (México y Centroamérica), Hollander (1996: 61) sostiene que "los parámetros de la misoginia se ensanchan hacia la sociedad entera y generan actitudes antagónicas hacia las mujeres". Además, la violencia psicológica, económica y los feminicidios se perpetran para humillar a las mujeres y sus comunidades, pues son expresiones de visiones patriarcales profundamente arraigadas en la sociedad. Esta violencia de género genera también miedo entre las mujeres, lo que ancla el dominio del sistema patriarcal, donde la falta de aplicación de la ley aumenta la impunidad.

Estos comportamientos tan sólo muestran la punta del iceberg de la agresión y violencia de género impuestas y perfeccionadas por sociedades patriarcales a lo largo de milenios. Superarla significa desarrollar y vigilar políticas públicas que no sólo promueven la igualdad en el acceso a bienes, trabajo, cargos, poder y salarios, sino que también compensan mediante sistemas de cuotas, las desigualdades y la violencia históricamente generadas además de perseguir los delitos por violencia de género. Si ocurriera esta transición, se beneficiarían no sólo a las mujeres, sino al conjunto de la sociedad. Se contribuiría a la construcción social de relaciones distintas de género, es decir que se favorecería una masculinidad y feminidad 
distinta que permitiría reducir la violencia en general y mejorar las relaciones de cuidado entre los géneros.

El índice de paridad de género de McKinsey (2015) analizó en 95 países de 10 regiones las diferencias entre salarios de hombres y mujeres. El nivel más bajo de equidad de género se registró en la India, seguida en Asia meridional, el Oriente Medio y África. El nivel más alto de equidad de género existió en los Estados Unidos y Australia con una puntuación de 0.74, seguido por Europa Occidental con 0.71. Estas diferencias globales indican que se requiere todavía de un largo camino para lograr una equidad de género en cualquier parte del mundo. El mismo Informe McKinsey sostiene que en un escenario de mediana equidad de género se podrían añadir 12 millones de millones de dólares o 11\% al PIB mundial en el año 2025. En el caso de una equidad total de género, en la que las mujeres desempeñan un papel idéntico al de los hombres en los mercados de trabajo y en el ejercicio de poder, se podrían acrecentar 28 millones de millones o $26 \%$ al PIB mundial en 2025, disponibles para superar los rezagos existentes (Woetzel, et al., 2015).

\section{CONCLUSIONES}

Ante las preguntas en este artículo quedó claro que el patriarcado es muy diverso en el mundo, pero que cuenta con características estructurales similares que ha impedido que la humanidad en el siglo XXI pudiera alcanzar el desiteratum de vivir en armonía, paz, seguridad, igualdad y cooperación con los demás en un entorno sustentable. El ejercicio del poder de los últimos cinco mil años en manos de hombres autoritarios y violentos no sólo ha generado dos guerras mundiales y una larga guerra fría en el siglo XXI, sino que ahora por intereses económicos mezquinos han emergido grupos transnacionales de poder que han provocado con gobiernos aliados una crisis ambiental descomunal y de civilización, que amenaza hasta la supervivencia de toda la humanidad y el planeta.

Ante este sistema andrógeno, socio-ideológicamente arraigado, es necesario entender el origen del sistema destructor y revertir las bases profundamente arraigadas en el patriarcado. Los cambios paradigmáticos como patrón del avance de la ciencia ocurren sólo cuando el paradigma acutal no explica los fenómenos nuevos y se requiere de sucesivas transiciones que finalmente terminan en una revolución paradigmática (Kuhn, 1962). En el caso de la doble crisis en referencia, las teorías de paz y seguridad elaboradas por hombres no han logrado entender los orígenes de la violencia. Betty Reardon (1996) vinculó el sexismo con las guerras y la violencia como método de control del sistema patriarcal, lo que abrió el potencial hacia una transformación radical. Posteriormente, feministas e investigadores de paz han desarrollado un enfoque sistémico holístico que apunta hacia alternativas radicalmente distintas. Carinee Kumar (2003) insiste en la pluralidad de las civilizaciones, donde se originan nuevas cosmologías.

Si se toma en cuenta dicha recomendación civilizatoria glocal (global y a la vez, local), se pudiera proponer una HUGE (humana, de género y ambiental) paz y seguridad engendradas y sustentables, que superaría la paz negativa y la seguridad limitada militarpolítica con la paz y seguridad positiva, estructural, sustentable, cultural y engendrada (ver Figura 3 más adelante). Esto es relevante, puesto que los vínculos entre paz y seguridad integral superan la ausencia de guerra y analizan los elementos requeridos para promover la noviolencia activa (ahimsa) y la armonía entre géneros y grupos sociales, raciales y étnicos diversos (Oswald, et al., 2014).

Estudios de la Paz y el Conflicto, Revista Latinoamericana, IUDPAS-UNAH, Volumen X, Número X, enero-junio 2020, pp. 116-142. DOI: 10.5377/rlpc.v1i1.9519 
A partir de la paz positiva, se pueden incorporar los elementos estructurales de la seguridad humana con sus cinco pilares (ausencia de miedo, ausencia de necesidades, ausencia de eventos extremos o desastres, vivir con libertad en un Estado de derecho y disfrutar de la diversidad cultural), ya que no hay armonía, ni seguridad, cuando las necesidades básicas de los seres humanos no están cubiertas (Annan, 2005). La desigualdad y la explotación son mecanismos que limitan el desarrollo pleno de las sociedades posmodernas, crean conflictos, violencia, discriminación y descontentos que se expresan en lo individual (en enfermedades físicas y mentales) y en lo social (en anomía, individualismo, violencia, egoísmo, conflictos sociales y rebeliones).

El anhelo de un crecimiento económico con equidad social es factible, ya que existen los bienes naturales, humanos, tecnológicos, políticos, económicos y culturales necesarios para garantizar alimentos, vivienda, trabajo, salud y bienestar a todos los seres humanos en el planeta. La desigualdad es resultado de relaciones autoritarias de poder, donde se infringen los derechos humanos y los civiles. No obstante, los modelos de participación democrática, cuotas que protejan y empoderen a minorías, cursos de conciliación de conflictos y mediación en situaciones de tensión, pueden reducir la violencia estructural y física. Además, países con mayor igualdad tienen mejores expectativas de vida, menos violencia y mejor calidad de vida (Suecia, Noruega), comparados con países con un PIB más alto, pero con desigualdad (Estados Unidos, Australia) (Wilkinson y Pickett, 2009).

Herman Daly (2014) muestra además en su modelo de crecimiento económico y beneficios marginales (costos para producir la unidad adicional de calidad de bienes o servicios) que los costos tienden a crecer y los beneficios a decrecer con cada unidad adicional de crecimiento. Esto significa que hay que detener el crecimiento cuantitativo del PIB cuando los costos marginales son iguales a los beneficios marginales y esto llevaría a modelos económicos distintos, donde se pudiera promover la descarbonización y desmaterialización de la economía. Esa propuesta coincide con muchos ecologistas que insisten que las externalidades tienen que incluirse en los costos de producción y los empresarios deberían pagar por los daños provocados en el ambiente y no como ahora la sociedad mediante desastres, enfermedades, contaminación y alimentos tóxicos. La racionalidad económica que se desarrolló a costo de la depredación ambiental y la destrucción de los servicios ambientales es cortoplacista. Con el fin de seguir contando con los servicios ecosistémicos donde la naturaleza provee, regula, soporta y permite desarrollar servicios culturales de manera gratuita, es necesario vincular el concepto de paz sustentable con el análisis de las cuatro fases de seguridad ambiental.

En el pasado, en un mundo poco poblado, el capital natural era un bien común y no tenía precio ni propietario. Al escasearse los bienes naturales, los economistas pusieron precios al capital natural y lo privatizaron. Otra manera de valorar y sobre todo, conservar el capital natural, fue reconocer su escasez e imponer cuotas de extracción (veda en el uso de agua) o de emisiones (impuestos al carbono). No obstante, recursos escasos han generado conflictos y guerras, por lo que la paz y seguridad engendradas y sustentables implican conservar los bienes naturales, evitar su contaminación y compartirlos de manera equitativa y de acuerdo con las necesidades de la naturaleza.

De acuerdo con Kumar (2003), los “universalismos civilizatorios" se articulan en lo local, a partir de prácticas diarias diversas y coherentes con ecosistemas, historias y tecnologías desarrolladas, además de organizaciones sociales existentes, lo que ha facilitado históricamente la consolidación de culturas diversas.

Estudios de la Paz y el Conflicto, Revista Latinoamericana, IUDPAS-UNAH, Volumen 1, Número 1, enero-junio 2020, pp. 116-142. DOI: 10.5377/rlpc.v1i1.9519 
La paz y seguridad engendradas y culturales incluyen el conjunto de saberes y creencias que encauzaron las conductas sociales, tanto en el acceso material como espiritual de los bienes. Facilitan la convivencia humana y a la vez, ayudan a superar estructuras sociales despóticas, misoginias, violentas y discriminativas. En toda conquista, rebelión o guerra, el control cultural era crucial para imponer tributos, sistemas sociales de esclavitud, relaciones feudales, explotación de personas o de recursos naturales y apropiación de la civilización. Al superar esta violencia, se requiere de un tipo liberador de paz y seguridad, ya que mediante la educación reflexiva (Freire, 1992) se logran transiciones positivas. Valores y comportamientos noviolentos y negociaciones pacíficas de conflictos permiten superar las diferencias existentes y solucionar controversias mediante el diálogo entre personas, grupos y naciones.

Las transformaciones culturales profundas cuestionan el origen de la violencia, la explotación y la discriminación, donde encuentran en el sistema patriarcal la base de todos los regímenes posteriores de relaciones sociales de producción, estratificación social y de despojo. En este sentido, la seguridad de género o engendrada (Serrano, 2009; Oswald, 2009) y la paz engendrada develan el vínculo entre las relaciones estructurales que impiden a la humanidad a vivir en armonía con su entorno natural y con los demás seres humanos.

La visión de paz y seguridad engendradas y sustentables obliga a cuestionar los trasfondos del sistema capitalista y abre caminos hacia la economía del regalo o solidaria. En lugar de intercambios calculados con ventajas, se ofrecen regalos sin otro interés que el bienestar del otro (Vaughan, 1997). Similar a la naturaleza que regala los servicios ecosistémicos, la economía de regalo de la sociedad se basa en intercambios regalados, servicios, bienes y conocimientos con las personas que lo requieran, cuidando a todos de que tengan lo necesario para vivir y desarrollarse sustentablemente. Esta transición hacia la economía del regalo promueve la identificación de las necesidades y la manera de satisfacerlas crea significados mediante el lenguaje y la práctica en la vida cotidiana. La intersección entre cuidar, estar para otros y asumirlo como suyo representa un valor profundo y es parte fundamental de lo humano y de la cultura de paz. Abre caminos hacia un mundo diferente, donde se valoran los bienes de subsistencia, los mercados locales, el trueque, la diversidad cultural, el cuidado ambiental y el bienestar social. Al promover en la investigación para la paz y la seguridad este paradigma alternativo se inician cambios conscientes en la sociedad que puedan propagarse y promuevan el valor de uso entre los demás sobre el valor de cambio del sistema capitalista.

A su tiempo, al cambiar el objeto de referencia de la paz y seguridad tradicionalmente fincado en el Estado hacia los grupos oprimidos (en especial mujeres, niñas, minusválid@s), las amenazas ya no se refieren a otros Estados o grupos terroristas, sino hacia las relaciones patriarcales. Los valores en riesgo, en lugar de la soberanía y la defensa legítima del territorio, se convierten en igualdad, equidad, representaciones sociales igualitarias e identidad de los individuos y grupos minoritarios.

Al integrar gráficamente los diferentes tipos de paz y seguridades, se llega a la HUGE paz y seguridad engendradas (Figura 3), donde la sociedad vive en armonía con la naturaleza y con otros grupos, resuelve sus conflictos de manera noviolenta, respeta y promueve la diversidad cultural, toma en cuenta la sabiduría tradicional y la integra en los conocimientos modernos, pero sin caer en tecnologías riesgosas (Beck, 1999) que amenazan la supervivencia de los seres humanos y el planeta.

Un tema crucial es la recuperación ambiental y el reto de procesos productivos y de consumo sustentables. Las cinco transiciones propuestas representan un cambio 
paradigmático que conduciría a las minorías y mayorías de pobreza críticas a empoderarse frente a los modelos de desarrollo depredadores y promover entre la sociedad consciente alternativas capaces de convencer a las instancias internacionales, nacionales y transnacionales, a emprender senderos alternativos hacia procesos de desarrollo con igualdad donde la equidad de género abre perspectivas de un futuro justo, equitativo y sustentable.

\section{Figura 3: HUGE paz y seguridad engendradas y sustentables.}

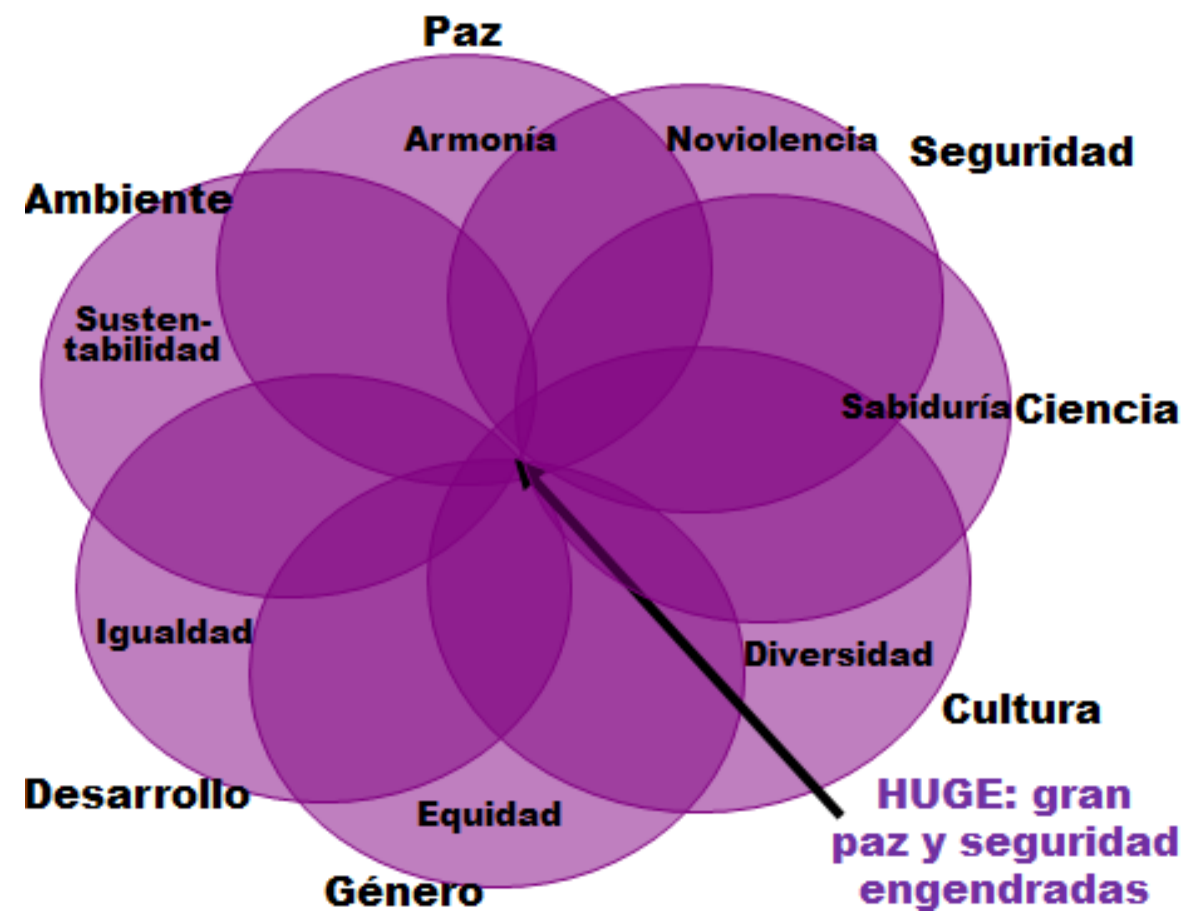

Los capitales naturales: suelo, agua, aire, energía, servicios ecosistémicos, genes, biodiversidad; económicos: mano de obra, capital, tecnología, ciencia, mercados, conocimientos; políticos: teorías, dirigentes, políticas, comunicación, participación, colaboración; y socio-culturales: familia, comunidades, cultura, educación, valores, principios, solidaridad, identidad, representaciones sociales, terapias, salud, bienes materiales e inmateriales; los intercambios están disponibles para promover modelos alternativos del quehacer diario y del desarrollo de sociedades rezagadas. De la humanidad como comunidad mundial y como individuos, depende promover la HUGE paz y seguridad engendradas y sustentables, una utopía en la que todos los seres humanos puedan vivir en armonía consigo mismo, con los demás y con su entorno natural.

El cambio paradigmático es urgente y necesario. Por ello, este artículo cuestiona las raíces de la violencia tan profundamente arraigada en el patriarcado que se ha hecho natural, al igual que la desigualdad, la explotación y la discriminación. Con el fin de superar los conflictos múltiples del capitalismo postmoderno y ofrecer al planeta Tierra y a la humanidad una oportunidad de supervivencia, es necesario cambiar el paradigma de los últimos milenios y promover una sociedad culturalmente diversa que sea capaz de igualar lo inigualado y de maternar a los demás y a la naturaleza. Ante las amenazas globales es urgente cambiar el paradigma andrógino y promover una vida plena en armonía con la naturaleza y con los demás seres humanos. 


\section{REFERENCIAS}

Annan, K. (2005). In Larger freedom: development, security and human rights: The Millennium Report. Nueva York: ONU.

Arach, (2018). "Como un ejército en territorio enemigo'; acerca de la violencia epistémica en la expansión magaextractivista". En Oswald, Ú. y Serrano, S. (Coords.), Riesgos socioambientales, paz y seguridad en América Latina. Cuernavaca: CRIM-UNAM, 123138.

Beck, U. (1999). World Risk Society. Cambridge: Polity Press.

Beck, U. (2011). "Living in and Coping with World Risk Society". En Brauch, H.G., Oswald, Ú., Mesjasz, C., Grin, J., Kameri-Mbote, P., Chourou, B., Dunay, P., Birkmann, J. (Eds.), Coping with Global Environmental Change, Disasters and Security. Heidelberg: Springer, 11-16.

Bennett, J.M. (2006). History Matters: Patriarchy and the Challenge of Feminism. Philadelphia: University of Pennsylvania Press.

BM (Banco Mundial) (2014). World Development Report. Risk and Opportunity. Washington: BM.

BM (2016). Poverty and Shared Prosperity. Washington: World Bank.

Brauch, H.G, Oswald, Ú., Mesjasz, C., Grin, J., Dunay, P., Chadha, N., Chourou, B., KameriMbote P., Liotta, P.H. (2008). Globalization and Environmental Challenges. Heidelberg: Springer.

Brauch, H.G. (2005). Environment and Human Security. Freedom from Hazard Impact, InterSecTions, 2/2005. Bonn, UNU-EHS.

Buzan, B.; Ole Wæver, J.W. (1998). Security: A New Framework for Analysis. Boulder: Lynne Riener.

Cabezudo, A. (2015). "Educación para la Paz y los Derechos Humanos: desafío pedagógico actual en América Latina”. En Serrano, S., Oswald, Ú., y de la Rúa, D., (Coords.), América Latina en el camino hacia una paz sustentable: herramientas y aportes. Guatemala: Respuesta para la Paz - FLACSO-CLAIP - CRIM-UNAM, 131-142.

Ceceña, A.E. (2014). “Del desarrollo al ‘vivir bien’: la subversión epistémica”. En Girón, A. (Ed.), Del "vivir bien” al "buen vivir", entre la economía feminista, la filantropía y la migración: hacia la búsqueda de alternativas. México: IIEc-UNAM, 11-22.

CEPAL (Comisión Económica para América Latina y el Caribe) (2019). Panorama social de América Latina 2019. Santiago: CEPAL.

CSH (Comisión de Seguridad Humana) (2003). Human Security Now. Nueva York: CSH.

Crutzen, P.J. (2002). “Geology of Mankind”, Nature, Vol. 415, N. 686, 23.

Czempiel, E. (1986). Friedenstrategien. Schöningh: Paderborn.

D’Eaubonne, F. (1974). Le Féminisme ou la Mort. Paris: Pierre Horay.

Daly, H. (2014). “Three limits to growth", Mother Pelican, Vol. 10, N. 10.

FAO (Organización de las Naciones Unidas para la Alimentación y la Agricultura) (2000). A Millennium without Hunger. Roma: FAO.

FAO (2014). The Food Wastage Footprint. Full Cost Accounting. Roma: FAO.

Freire, P. (1968). Pedagogia do Oprimido. Rio de Janeiro: Paz et Terra.

Freire, P. (1992). Pedagogia da esperança: um reencontro com a Pedaogia do oprimido. Río de Janeiro: Paz e Terra.

Estudios de la Paz y el Conflicto, Revista Latinoamericana, IUDPAS-UNAH, Volumen X, Número X, enero-junio 2020, pp. 116-142. DOI: 10.5377/rlpc.v1i1.9519 
Fukuyama, F. (1992). The End of History and the Last Man. Nueva York: Free Press.

Galtung, J. (1968). "Peace", en International Encyclopedia of the Social Sciences. Londres: Mcmillan, 487-496.

Galtung, J. (1985). Sobre la Paz. Barcelona: Fontamara.

Gasca, J. (2014). "Comunalidad y gestión social de los recursos naturales en la Sierra Norte de Oaxaca”. En Marañón Pimentel, B. (Ed.), Buen vivir y descolonialidad. Crítica al desarrollo y la racionalidad instrumentales. México, D.F.: IIEc-UNAM.

Hollander, C. (1996). "The Gendering of Human Rights: Women and the Latin American Terrorist State", Feminist Studies, Vol. 22, N. 1.

IEA (Agencia Internacional de la Energía) (2014). World Energy Investment Outlook, (Disponible online: www.iea.org/publications/freepublications/publication/weio2016.pdf)

IPCC (Panel Intergubernamental del Cambio Climático) (2014). Climate Change 2014: Impacts, Adaptation, and Vulnerability. Cambridge: Cambridge UP.

IPCC (2018). Summary for Policymakers of IPCC Special Report on Global Warming of $1.5^{\circ} \mathrm{C}$ approved by governments. Cambridge: Cambridge UP.

IPCC (2019). The Special Report on Ocean and Cryosphere in a Changing Climate. Cambridge: Cambridge UP.

IRENA (Agencia Internacional de las Energías Renovables) (2019). Renewable Energy Statistics 2019. Paris: IRENA.

Kuhn, T. (1962). La estructura de las revoluciones cientificas. México: FCE.

Kumar, C. (2003). Carta abierta al Secretario General de la ONU, $\mathrm{http}: / / w w w . n o d o 50 . o r g / c s c a / a g e n d a 2003 /$ con_iraq/nota_1-04-03.html

Lagarde, M. (1990). Los cautiverios de las mujeres. Madresposas, monjas, putas, presas y locas. México: PUEG/UNAM.

López, M. (2004). Enciclopedia de Paz y Conflictos. Granada: Universidad de Granada.

MA (Evaluación de los Ecosistemas del Milenio) (2005). Ecosystems and the Human WellBeing. Washington, D.C.: Island Press.

McKinsey Global Institute (2015). The Power of Parity: How Advancing Women's Equality Can Add \$12 Trillion to Global Growth. Nueva York: McKinsey Global Institute.

Mies, M. (1986). Patriarchy and Accumulation on a World Scale. Melborne: Zed Book.

ONU (Asamblea General de las Naciones Unidas) (1998). Resolución A/52/13, 15 de enero, Sesión 52, Asunto 156 de la Agenda. (Disponible online: https://www.um.es/paz/resolucion2.html)

ONU (1999). Resolución A/53/243, 6 de octubre, sesión 53, Tema 31 del programa, Declaración y Programa de Acción sobre una cultura de paz. (Disponible online: http://www.fund-

culturadepaz.org/spa/DOCUMENTOS/DECLARACIONES,\%20RESOLUCIONES/Dec laracion_CulturadPaz.pdf).

Oswald Spring, Ú. (2009). “A HUGE Gender Security Approach. Towards Human, Gender and Environmental Security”. En Brauch, H.G., Behera, N.C., Kameri-Mbote, P., Grin, J., Oswald Spring, Ú., Chourou, B., Mesjasz, C., Krummenacher, H. (eds.), Facing Global Environmental Change. Environmental, Human, Energy, Food, Health and Water Security Concepts. Heidelberg: Springer, 1165-1190.

Oswald Spring, U. (2011). "Towards a sustainable health policy in the Anthropocene", Magazine of the International Human Dimensions Programme on Global Environmental Change (IHDP-ICSU), N. 1, 19-25.

Estudios de la Paz y el Conflicto, Revista Latinoamericana, IUDPAS-UNAH, Volumen 1, Número 1, enero-junio 2020, pp. 116-142. DOI: 10.5377/rlpc.v1i1.9519 
Oswald Spring, Ú. (2013). "Dual vulnerability among female household heads", Acta Colombiana de Psicología, Vol.16, N. 2, 19-30.

Oswald Spring, Ú., Serrano, S.E, Estrada, A., Flores, F., Ríos, M., Brauch, H.G., Ruiz, T., Lemus, C., Estrada, A., y Cruz, M. (2014). Vulnerabilidad social y género entre migrantes ambientales. Cuernavaca: CRIM-UNAM.

Oswald Spring, Ú. y Brauch, H.G. (2009). Reconceptualizar la seguridad en el siglo XXI. Cuernavaca: CRIM-UNAM.

PNUD (Programa de Naciones Unidas para el Desarrollo) (1994). Human Development Report 1994. New Dimensions of Human Security. Nueva York: Oxford UP.

PNUD (2014). Informe sobre Desarrollo Humano. Sostener l Progreso Humano: Reducir vulnerabilidades y construer resiliencia. Nueva York: PNUD.

Reardon B. (1996). Sexism and the War System. New York: Syracuse University Press.

Reardon, B. y Snauwaert, D. (2014). Betty A. Reardon: A Pioneer in Education for Peace and Human Rights. Cham: Springer.

REN21 (2014). Renewable Energy Policy Network for the 21st Century. París: REN21.

Schumacher, E.F. (1999). Small is beautiful. Stuttgart.

Senghaas, D. (1997). Frieden machen. Frankfurt a. Main: Surkamp.

Serrano Oswald, S.E. (2010). La Construcción Social y Cultural de la Maternidad en San Martín Tilcajete, Oaxaca. Tesis Doctoral. México D.F: Instituto de Antropología de la UNAM. UNAM.

Serrano Oswald, S.E. (2009). "Endendering Security", en Brauch, H.G. et al. (eds.), Facing Global Environmental Change. Environmental, Human, Energy, Food, Health and Water Security. Berlin: Springer, 1151-1164.

UNCCD (Convención de las Naciones Unidas de Lucha contra la Desertificación) (2019). Land Degradation Neutrality. Transformative Actions. Bonn: UNCCD.

UNESCO (Organización de las Naciones Unidas para la Educación, la Ciencia y la Cultura) (2013). Culture of Peace and Non-Violence. A vision in action. Paris: UNESCO.

Vaughan, G. (1997). For-Giving. A Feminist Criticism of Exchange. Austin: Plain View Press.

Wæver, O. (2008). "Peace and Security. Two Evolving Concepts and Their Changing Relationship". En Brauch, H.G, Oswald Spring, Ú., Mesjasz, C., Grin, J., Dunay, P., Behera, N.C., Chourou, B., Kameri-Mbote, P., y Liotta, P.H (Eds.), Globalization and Environmental Challenges: Reconceptualizing Security in the 21st Century, Hexagon Series Vol. 3. Berlin: Springer, 99-112.

WHO (Orgamización Mundial de la Salud) (2019). State of Global Air 2019 Report. Ginebra: WHO.

Wilkinson, R., y Pickett, K. (2009). The Spirit Level: Why More Equal Societies Almost Always Do Better. London: Allen Lane.

Woetzel, J., Madgavkar, A.; Ellingrud, K.; Labaye, E; Devillard, S.; Kutcher, E.; Manyika, J.; Dobbs, R.; Krishnan, M. (2015). The Power of Parity: How Advancing Women's Equality can add \$12 Trillion to Global Growth. Bruselas: McKinsey Global Institute (MGI).

WWF (Fondo Mundial para la Naturaleza) (2016). Living Planet Report 2016 (Disponible online: http://www.worldwildlife.org/pages/living-planet-report-2016). 


\section{REFERENCIA DE LA AUTORA}

Úrsula Oswald Spring es investigadora del Centro Regional de Investigaciones Multidisciplinarias-UNAM. Ganó la primera cátedra sobre Vulnerabilidad Social en la Universidad de las Naciones Unidas. Estudió medicina, psicología, filosofía, lenguas, antropología y ecología en Madagascar, Paris, Zúrich y México. Fue Secretaria de Desarrollo Ambiental en Morelos y la primera Procuradora de Ecología. Fue y sigue siendo miembro del IPCC, PINCC, ISSC, IIASA y RIOCC-Adapt de Iberoamérica. Ha escrito 57 libros y 398 artículos científicos/capítulos y obtuvo múltiples premios: $4^{\mathrm{a}}$ década de la ONU, Sor Juana, Mérito Ecológico, Mujer Académica, Women of the Year 2000, Medalla Emiliano Zapata (2016) y el mérito por 50 años de investigación, entre otros.uoswald@gmail.com.

Recibido: 12-12-2019

Aceptado: 19-12-2019

(c) (i) Licencia Creative Commons Reconocimiento 4.0 (CC BY 4.0). 